\title{
Crise econômica e espaços de origem ressignificados: rearranjos de imigrantes brasileiros retornados da Itália
}

\author{
Economic crisis and spaces of origin re-signified: \\ rearrangements of immigrants and the returnees of Italy \\ Joao Carlos Tedesco*
}

Palavras-chave:

Brasileiros

Imigração

Retorno

Keywords:

Brazilian

Immigration

Return

\begin{abstract}
Resumo: O estudo analisa aspectos da imigração de retorno; focaliza imigrantes brasileiros retornados da Itália, nos seus espaços de origem, em alguns municípios do sul do Brasil; dá ênfase à multiplicidade de processos envolvidos na decisão de retornar, às dificuldades de reintegração e às possíveis reemigrações. A partir de pesquisa de campo in loco e entrevistas diretas, vimos que a realidade é dinâmica, ou seja, se permanecer no país de destino não há garantia de tempo, o tempo do retorno passa pela mesma lógica. Insistimos no fato de que precisamos ver as motivações econômicas e as não econômicas do retorno. Há um conjunto amplo e variado de situações, justificativas, explicações, racionalizações que acabam criando realidades de retorno, de volta ao país que emigrou antes ou a outro. Nesse sentido, as situações são complexas e tornam difíceis as generalizações.
\end{abstract}

\begin{abstract}
The study of the theoretical aspects of return immigration; focuses Brazilian immigrants returned from Italy to their places of origin in some municipalities in southern Brazil; emphasizes the multiplicity of processes involved in the return decision, the difficulties of reintegration and possible re-emigrations. From field research in loco and direct interviews, we saw that the reality is dynamic, in other words, if you stay in the destination country there is no guarantee of time, the time of return goes through the same logic. We insist on the fact that we need to see the economic and non-economic motivations of return. There is a wide and varied set of situations, justifications, explanations, rationalizations that end up creating realities of return, back to the country that emigrated before, or to another. In this context, how situations are complex and become generalizations.
\end{abstract}

Recebido em 27 de março de 2018. Aprovado em 25 de julho de 2018.

\section{Introdução}

O imigrante é, por excelência, um sujeito sociocultural em movimento (SACCO, 2007; SAYAD, 2000); tempo, espaço e vividos movemse juntos. Esse processo implica desenraizamentos e reenraizamentos constantes, vidas em dois universos que se transnacionalizam e jamais serão iguais e do mesmo jeito para quem os deixou e quem ficou (BAUMAN, 2017). Há, nessa ação, separações, ritmos de vida, recomeços variados e criação de novas (situ)ações. Na realidade, como diz Sayad (2000), os locais de origem tornam-se tão importantes quanto os de destino.

Entendidos assim, os imigrantes incorporam a identidade de um sujeito de múltiplas fronteiras (RAMOS, 2003; BAUMAN, 2017), ou seja, alguém que delimita e separa tempos, espaços, contextos, distâncias e vividos cotidianos; tornamse, também, em grande parte - de uma forma ou de outra - estranhos ao local de destino, mas, também, no de origem (ASSIS; CAMPOS, 2009; SAYAD, 2000). Diferenças, distâncias e ausências físicas são processos socioculturais e confins demarcadores de

\footnotetext{
* Doutor em Ciências Sociais pela Universidade Estadual de Campinas (UNICAMP), pós-doutorado nas Universidade de Verona e Milão. Professor do Programa de Pós-Graduação em História da Universidade de Passo Fundo (UPF). Pesquisador do tema das migrações, dos processos de colonização no norte do Rio Grande do Sul e de conflitos agrários.
} 
existências individuais, grupais e territoriais; disso, resultam saídas e retornos constantes, temporários ou definitivos; reemigrações ou não (AMBROSINI, 2008).

Nessa questão de múltiplas fronteiras e territórios, o retorno é um fator importante na identidade de imigrante (ASSIS, 1995). É uma ação que promove o reencontro de múltiplas dimensões. A grande questão é a concepção relacionada a um conjunto de coisas materiais, pessoas, afetividades e interações constituídas ou não no período da ausência. Em geral, o retorno pode revelar o desejo do imigrante em se reencontrar (RAMOS, 2003; SAYAD, 2000), coligar-se com seus pontos de referências e de pertencimento, com o que estava próximo no ato da saída e sentiu falta no decorrer da ausência, com os familiares e parentes (DURAND, 2006; DIAS, 2000). O tempo de imigrante é de desencontros em relação aos anteriores e em relação aos que o contato com o novo cenário produziu nele (BAUMAN, 1999).

Tendo presente algumas dessas ideias, buscamos analisar o ato de retornar ao local de origem por alguns imigrantes brasileiros que estavam na Itália. O estudo faz parte de uma pesquisa maior que estamos empreendendo, a qual busca correlacionar imigração e desenvolvimento no local de origem ${ }^{1}$. Nesse projeto maior, buscamos compreender aspectos da imigração de brasileiros para a Itália a partir do local de origem, enfatizando a dinâmica econômica que se produz, a centralidade da família, os processos de saídas, as ações de cooperação existentes entre a região do Vêneto com alguns municípios do Rio Grande do sul, em particular, os acordos de gemellaggios e os vínculos que se constituem com o espaço de destino e o retorno ao local de origem.

Em torno desse último aspecto é que organizamos alguns elementos de pesquisa no presente texto. A pesquisa de campo foi realizada junto a 31 imigrantes ( 26 homens e 5 mulheres) no interior de suas famílias nos municípios de Pato Branco, Guarapuava e Dois Vizinhos, situados no Paraná; Água Doce, Luzerna, Criciúma, Treze Tílias e Joaçaba, em Santa Catarina; em Nova Prata, no Rio Grande do Sul, por serem locais de grande fluxo de saídas e onde tivemos melhores contatos e possibilidades de acesso em razão da existência de imigrantes que havíamos conhecido na Itália em anos anteriores ${ }^{2}$.

Estivemos nesses municípios em vários dias entre os meses de julho a dezembro de 2017. Já havíamos estado em alguns deles em alguns dias dos anos de 2011 e 2015, em geral no mês de julho e/ou no final do ano por ocasião de nossas férias letivas. Com isso, fomos percebendo processos que se alteram e outros que se preservam, períodos de forte presença de imigrantes na Itália bem como de retornados 3 . Em 2015 e 2017, percebemos um grande fluxo de retornados - principalmente da Itália -, bem como de tentativas de reemigrações, pós-2016, para outros países como Canadá, Estados Unidos, Áustria e Austrália. Estivemos na Itália, em particular, na Universidade de Verona, nos meses de janeiro e fevereiro de 2018, em um estágio de professor visitante. Nesse período, tivemos oportunidade de entrevistar imigrantes brasileiros na região do Vêneto (Verona e Vicenza com mais intensidade) e na Lombardia (regiões do Lago de Garda pertencente à Província de Bréscia) ${ }^{4}$.

Constituímos nosso texto, sinteticamente, esboçando alguns aspectos da imigração brasileira na Itália com a intenção apenas de atualização de informações, demonstrando processos históricos que se renovam e produzem fluxos migratórios. Posteriormente, centramos nossa análise na questão do retorno de imigrantes para os locais de origem dando ênfase a múltiplos fatores que produzem essa ação, implicações nos espaços de destino, obrigações, pontos de estrangulamentos no espaço de origem e nos próprios imigrantes, reemigrações, presenças e ausências como dinâmicas de um mesmo processo. O que buscamos é perceber que o retorno é parte integrante da imigração; ele não é um fim, faz parte da dimensão circulatória da imigração; depende de múltiplos processos e revela realidades múltiplas e centradas em vários fatores. Buscamos ter presente que a emigração não é necessariamente projetada como definitiva para o sujeito que a viabiliza, assim como não o é o retorno (SAYAD, 2000); causalidades de uma (saída) podem servir também para o outro (retorno). As situações vividas e concebidas no espaço de retorno podem também ser promotoras de novas saídas. 


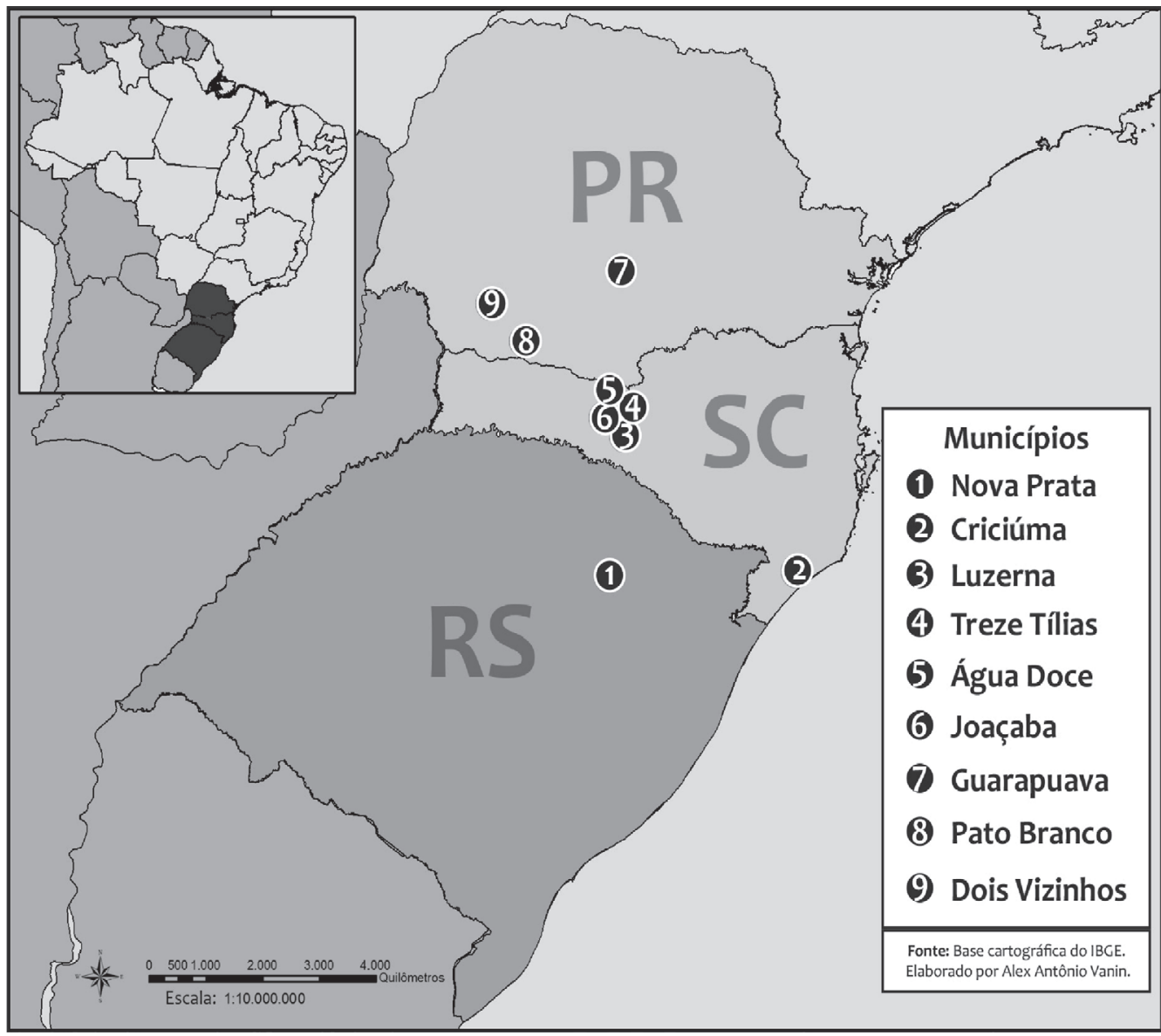

Mapa 1 - Municípios selecionados para nossa pesquisa de campo no sul do Brasil.

Fonte: Base Cartográfica do IBGE; elaborado por Alex A. Vanin, março de 2018.

\section{A imigração de brasileiros na Itália: representações e vínculos históricos}

A Itália é considerada como um dos países de emigrantes em razão da diáspora que se constituiu entre meados do século XIX até as primeiras décadas do século XX; porém, nos últimos 20 anos, já incorporou outra identidade: um lócus de imigrantes. É um dos países em que essa dinâmica se tornou intensa em razão de processos econômicos, demográficos, geográficos, culturais, de legislação etc. Em 2017, o país já ultrapassou a casa dos cinco milhões de imigrantes considerados regulares (FONDAZIONE IDOS, 2017, p. 13). Houve um aumento de mais de 3 milhões no último decênio. Significa afirmar que é um país com dinâmica migratória intensa e de uma forma abrupta, o que ocasiona grandes repercussões e que está no centro dos debates e manchetes cotidianas.
A emigração de brasileiros para a Itália, de uma forma mais intensa, não ultrapassa três décadas. É fruto de amplos processos que interligaram historicamente os dois países, da crise econômica do Brasil nas décadas de 1980 e 1990, da possibilidade de efetivação da dupla-cidadania e de políticas que favorecerem o retorno de oriundi à Itália, a qual, no período, necessitava de imigrantes e/ou pertencia tê-los de nacionalidades que, de uma forma ou de outra, possuíam referências de cultura ocidental e/ou, em particular, no horizonte da italianidade. Os acordos de gemellaggios ${ }^{5}$ também favorecem a emigração de brasileiros para a Itália.

Segundo dados do Dossier/Imigrantes de 2008, havia em torno de 140 mil brasileiros na Itália em 2007 (esse período, talvez, tenha sido o de maior quantidade no país). Houve uma redução para, aproximadamente, 80 mil em 2010, e, em 2016/2017, registraram-se aproximadamente 
50 mil imigrantes (esse dado difere muito dos do Itamaraty, que estipula em torno de $82 \mathrm{mil})$. Os dados na Itália não contabilizam os que já possuem a dupla-cidadania, pelo fato de que os imigrantes não necessitam demandar regularização em suas repartições públicas que tratam disso, como o fazem os outros. A redução de imigrantes, em geral, deve-se à crise econômica da Itália (Europa, de uma forma em geral) e seus reflexos no horizonte da oferta e remuneração do trabalho. Muitos desses imigrantes não necessariamente retornaram ao Brasil e, sim, emigraram para outros países. Dois de nossos entrevistados, antes de retornarem ao Brasil, haviam reemigrado da Itália para outros países, no caso, um deles para o Canadá e outro para a Suíça.

Há algumas especificidades da imigração brasileira na Itália, dentre as quais, em 2016, era composta por $78 \%$ de mulheres em seu contingente geral. As regiões de maior concentração de brasileiros são as mesmas da emigração em geral da Itália para o Brasil, ou seja, na Lombardia com em torno de $12 \mathrm{mil}$, no Vêneto com aproximadamente 7 mil, no Piemonte com quase 6 mil e no Lazio em torno de 5 mil (CARITAS/MIGRANTES, 2011; FONDAZIONE IDOS, 2017).

A denominada "emigração de retorno" (aos descendentes) é expressão de uma identidade de "bons imigrantes"; em geral, ela tende a ser auxiliada, pois são os considerados mais adaptados (ZINCONE, 2006), os que, em teoria, terão melhor capacidade de assimilação para o trabalho, à cultura italiana etc. As regiões Norte e Nordeste do país (Vêneto e Lombardia), espaços de grande presença de brasileiros, são as que forneceram grande parte dos fluxos de saída de imigrantes para o Brasil entre a segunda metade do século XIX e primeira do século XX. Portanto, há vínculos culturais, dialetais, religiosos, étnicos entre regiões do Brasil com essas da Itália.

A imigração brasileira é vista como tendo uma capacidade muito grande de se adaptar a um mercado de trabalho, em geral, no terciário, com certa correspondência linguística (muitos descendentes falam algum tipo de dialeto de origem italiana, readaptado em razão das condições da vida nas colônias e em outros lugares de inserção) e vizinhança cultural dos países; é o chamado efeito "cittadinanza di ritorno", denominado por alguns como oriundi (ZINCONE, 2006). Essas relações produzem fluxos transnacionais, redes de relações, capital social, em geral, envoltos e justificados pelo viés étnico e familiar e, em especial, de nível regional, tanto na Itália quanto no Brasil. Porém, é bom enfatizar que nem todos(as) os(as) imigrantes possuem esses vínculos histórico-culturais com a Itália.

$\mathrm{O}$ fato de haver processos que viabilizam a dinâmica da emigração para a Itália, não significa que sejam eficazes na manutenção deles no país de destino; há retornos. O retorno é parte integrante desse processo, porém, em grande parte, como expressão contraditória.

\section{O retorno ao local de saída: múltiplos rearranjos e simbologias}

$\mathrm{O}$ ato de retornar ao espaço de origem, em geral, induz à racionalização dos alcances da saída e da projeção efetuadas quando da identidade de imigrante; avalia o alcance dos objetivos previamente propostos e/ou previstos (SOARES, 2009). Nem sempre pode ser expressão de uma ação negativa, ou seja, de que o empreendimento emigratório não deu certo, pois não atingiu objetivos econômicos e financeiros idealizados (DURAND, 2006). Há outros elementos que estão no cenário do ato de retornar e que transcendem desejos e intenções previamente definidos. Doenças, crise de empregos, crise econômica, não obtenção de renovação de visto, expulsão, algum outro tipo de infortúnio etc., podem fazer parte dessa decisão. Portanto, há elementos subjetivos e há fatores externos condicionantes, envoltos nas questões econômicas, de ordem familiar, identitária, afetiva, de legislação do país hospedeiro etc. (ASSIS; CAMPOS, 2009).

Em nossas entrevistas, dos 31 interlocutores, 16 enfatizaram o problema econômico, expresso no desemprego e na redução do valor e da quantidade de horas diárias trabalhada, fato esse que promovia uma intensa redução dos ganhos semanais; três deram ênfase a problemas familiares (doença, cuidar dos pais com idade avançada), outros 
informaram estar se aposentando, sentiram que era o momento de retornar, pois já estavam há muito tempo na Itália; outros enfatizaram que queria investir no local de origem. Enfim, há vários fatores, dificilmente haja apenas um motivo, eles se interrelacionam, mas o fator econômico, pelo que vimos, é o que prepondera.

Na realidade, o retorno expressa rearranjos entre imigrantes enão imigrantes, em suasinterações, obrigações e situações específicas (SAYAD, 2000), bem como cenários socioeconômicos e normativos (ASSIS; CAMPOS, 2009). Não podemos deixar de insistir no fato de que o projeto migratório tem uma grande conotação familiar (DECIMO, 2005). O retorno se constitui como resultado disso; junto ao imigrante, em geral, há uma família, uma história mais ampla de relações, confrontos, obrigações e vínculos (HERRERA; CARILLO, 2010). São raros os imigrantes que decidem por conta própria deixar o local de origem ou de tentar uma aventura sem nenhum contato ou nenhuma referência que os mantenha ligados ao local de onde partiram (DURAND, 2006; DIAS 2000). Desse modo, é difícil perceber o fenômeno migratório sem romper com a visão dicotômica entre país de destino e de origem (AMBROSINI, 2010); ambos estão em profunda correlação. É por esse motivo que autores dão ênfase ao transnacionalismo migratório contemporâneo.

Imigrantes relacionam-se em locais múltiplos, tanto no espaço de destino, quanto de o de origem. Vista por essa ótica, a imigração revela indívíduos em ligações constantes, em redes informais e afetivas, que revelam obrigações e intenções profundas e significativas. Há uma lógica de afetos entre os que partem, os que ficam, os que exercem a mediação na circulação entre os dois, ligações parentais e proximidade identitária (AMBROSINI, 2010). O território afetivo muda, ou seja, há um movimento complexo entre lugares e pessoas. Trabalhar intensamente para ter recursos e enviar a familiares e/ou para empreender em algum momento, correlaciona-se com a moral familiar e com o dever de família. Nessa condição, o imigrante se transforma em um sujeito econômico transnacional que circula, por meio do dinheiro, de seus vínculos, da ponderação de seus gastos, investimentos, consumos e sua poupança entre um lugar e outro.

A dimensão transmigrante que, pelo menos em parte ou em alguns âmbitos, caracteriza tendencialmente $\mathrm{o}$ fenômeno migratório internacional, revela participação dos meios de comunicação, os quais favorecem para que imigrantes possam participar da vida social dos dois países (origem e destino). Esse transnacionalismo faz com que os confins políticos existentes entre as duas sociedades nacionais não constituem limites para a própria vida social e ao campo social de atividades (AMBROSINI, 2008).

Nas respostas que obtivemos em nosso estudo de campo, dos 31 questionários efetuados diretamente junto a imigrantes retornados, nove informaram que planejam e/ou já estão contatando possibilidades de reemigrarem para o local anterior ou outro dentro da Itália, ou, ainda, em outro país; dez informaram que desejam, mas ainda não efetuaram nenhuma ação concreta; um disse que está "vendo bem para não repetir erros anteriores", porque agora adquiriu mais experiência, fala italiano, já tem conhecidos, já está investindo no Brasil, adquiriu certo empoderamento e/o capital social e econômico, o que lhe permite barganhar e melhor decidir entre reemigrar e/ou permanecer como retornado; três deles não pretendem e um disse que ainda não sabe. Percebe-se que a dimensão da reemigração é também parte constituinte do retorno. As cinco mulheres entrevistadas estão nas que planejam retornar. Uma delas disse que não consegue adaptar-se no local de origem, "já fui pra Florianópolis, Balneário [Camboriú] ver se arrumava por lá, mas não deu; não consigo mais viver aqui, é muito pacato, as pessoas são diferentes ou eu fiquei diferente; não tem trabalho aqui. [...]; vou cuidar de velhinhos na Itália, é estressante e depressivo, mas é o que dá [...]".

Processos sociais e culturais vão se alterando em concomitância com as condições objetivas e subjetivas da realidade constantemente reconstruída pelo imigrante e, não se reproduz da mesma forma no espaço, no tempo, nem para as pessoas envolvidas (que podem não ser apenas os já emigrantes, mas os potencialmente e os de seu 
quadro de referência, em particular, as famílias). A dinâmica desses processos é intensa, variada, complexa e de difícil generalização.

\section{Os horizontes econômicos e das responsabilidades morais}

Há acordos que são produzidos em razão de dádivas e de dívidas (essas, financeiras) entre os que saem e os que ficam (DURAND, 2006; DIAS, 2000). Esses acordos exigem diálogos no interior das famílias, pressupõem muita confiança, ativação de valores morais e de horizontes da reciprocidade e solidariedade, bem como da lealdade, pois não é qualquer coisa que fica (podem ficar filhos, avós, pais, sogro(a), parentes, amigos, namorados(as), dentre outros), podendo haver, desse modo, fortalecimento dos papéis tradicionais de gênero ou, então, uma intensa alteração. Nas narrativas das cinco emigrantes retornados de nossa esfera de pesquisa, há nessa questão de gênero e de papéis considerados tradicionais na família, pouca mudança. Enfatizam que na Itália "sobram para nós fazer aquilo que fazíamos antes de sair". No espaço de retorno: "é tudo da mesma forma"; quando estava fora, muita coisa se alterou, mas desde que estou aqui, parece que nisso a velha realidade retorna [...]. Por isso, que é melhor voltar para a Itália, lá se faz mais dinheiro do que aqui; aqui não tem trabalho. A outra entrevistada, narra: "não adianta saber o italiano, até comecei a querer dar aula de italiano, mas não deu. Voltar a ser doméstica aqui; então, prefiro fazer isso lá que ganho em euro". Ela enfatiza: "estando lá, se tem mais responsabilidade pela família porque sabemos e sabem aqui que ganhamos mais. [...]". Diz a entrevistada que: "lá não se vive bem, mas tem trabalho, para nós lá tem; aqui se vive mais, se vive bem, mas não tem trabalho; aqui se tem lazer, mas não se tem dinheiro, lá é o inverso [...]".

A regularidade do envio do dinheiro a quem fica é fundamental para o bom andamento dos acordos e obrigações (HERRERA; CARILLO, 2010; MARTES; SOARES, 2006); aliás, esse processo compensa, vincula e correlaciona múltiplas questões na relação entre quem emigra e quem fica (DIAS, 2000). O dinheiro enviado expressa a importância da família, demonstra que ela não foi abandonada, que um dia o(a) emigrante retornará, por isso, também, além de obrigação de enviar, há, reciprocamente, responsabilidade e parcimônia nos gastos para quem recebe. Nesse sentido, há uma rede familiar que também é constituída e que se propõe a assumir funções, que, muitas vezes, é fortalecida pela situação de imigrante (PERROUD, 2007). Ou seja, uma espécie de família alargada constituída em grande parte pelos parentes que, frente a uma situação de necessidade e de remuneração, lança mão de práticas solidárias, hospitalidade e de possibilidade de ganhos, pois, como nos disse uma imigrante na Itália, que diz sustentar a mãe e uma irmã que se divorciou,

[...] eles acham que aqui ta o dinheiro, que temos a obrigação de auxiliar"; um outro imigrante retornado enfatizou, em conversa informal, que "quando recebia uma ligação da [nome da pessoa] era sempre para pedir dinheiro; foi até que cansei. A separação veio por causa disso. Eu servia só para mandar dinheiro. Achava que eu lá nadava no dinheiro. Esse povo não sabe como é a vida aqui (Imigrante brasileira, há quatro anos entre Itália e Áustria, oriunda de Joaçaba; atualmente trabalha em casa de família como cuidadora de idosos).

O retorno pode revelar certa consciência de nacionalidade, pertencimento a um espaço, a uma família no interior dos cenários de origem, ou seja, expressão de que se tem vínculos e "é para alguém que se trabalha, para os filhos", como revela um brasileiro entrevistado na Itália. É uma oportunidade para fazer ver que o fato de ter abandonado o grupo e a família, não foi feito unicamente por total vontade própria e, sim, pelas condições objetivas de oportunidades econômicas abertas externamente e dificultadas internamente (no local). É um ato que objetiva compensação e mudança de vida para si (quem emigra) e para outros que assumem responsabilidades que deveriam ser suas. 


\section{Racionalidades do retorno: planejamento, experiência migratória e crises}

Imigrantes entrevistados disseram que, ao partirem para a Itália, já projetaram seu retorno ainda que de uma forma simbólica, compensadora e/ou reparadora: "para pouco tempo"; "dois, três anos", mas, na realidade, "sabia que ia ficar mais, assim acomodei a mulher e a filha, ah, e a sogra". Como já falamos, vários responderam que, em razão da crise no Brasil, estão pensando em retornar para a Itália. "Fugimos das crises; lá [Itália] dizem que está um pouco melhor; já tive convites para voltar no trabalho que estava". Vimos também que o tempo de permanência como retornado também varia em razão de uma multiplicidade de fatores que vão além das decisões individuais e das projeções e promessas a priori feitas, da legislação nos países de destino (que também se altera), comumente em detrimento aos imigrantes, da remuneração atual e da possível no Brasil, do reagrupamento familiar, da obtenção da dupla-cidadania e de relações afetivas que se constituem em ambos os lugares.

Do total de entrevistados (31 retornados), nove responderam que já estão há mais de três anos no Brasil, 14 há menos de dois anos, quatro estão há aproximadamente dois anos, e, quatro, há menos de um ano. Os que disseram com mais convicção que pretendem retornar, em geral, são os que estão há menos de dois anos no espaço de origem. Talvez esse processo tenha correlação com a crise econômica no Brasil e a dificuldade de encontrar empregos e/ou de investir ou empreender em algum setor. Os que estão há mais tempo, já conseguiram se reinserir em processos produtivos variados; porém, ouvimos reclamações em torno dos ganhos financeiros auferidos e que isso poderá fazer alterar a situação de retorno definitivo. Dinâmicas estão em processos, múltiplos caminhos são desenhados e protagonizados por imigrantes, retornados e os não imigrantes em razão também de fatores variados e contingenciais.

Nesse sentido, imigrantes refletem e reavaliam sua qualidade de vida, projetam um sonho de melhor viver ao retornar ou incorporam melhores condições de vida no espaço hospedeiro (aumento do consumo, melhor habitação, aquisição de automóveis, motos, turismo, lazer etc.), alguns até optam por trabalhar menos, principalmente os que estão há mais tempo na Itália. Eles suprem a nostalgia e os problemas advindos da distância através de esferas de consumo; passam a ressignificar ambos os países, valorizar dimensões até então pouco visíveis e sentidas (RAMOS, 2003). Alguns nos diziam que, com o tempo, aumenta a saudade e a vontade de retornar; contudo, o círculo de relações fica muito em correspondência com as dinâmicas que envolvem a família, "por ela, eu voltaria, mas e aquela vida lá, trabalhar onde lá?". Outros nos disseram que, depois do primeiro retorno deliberado para visitar seus familiares, o cenário migratório fica melhor, "ai é que tu vês que estávamos bem lá", disse-nos um retornado de Nova Prata/RS.

\section{“Difícil se acostumar": transitoriedades, adaptações e ausências}

Em teoria, o retorno expressa um movimento de emigrantes de volta aos seus territórios de origem para se (re)fixarem. Esse (re)fixarem revela muitas nuances. Entrevistados informam que "estranharam muito as coisas aqui no Brasil" e, em particular, no local de origem. Já vimos que não é incomum o estranhamento ou o fato de se sentir estrangeiro muito mais em seu local de retorno. O local é, em grande parte, o mesmo, mas o tempo não o é mais, visto que as coisas e as pessoas desse local alteraramse junto com o tempo.

Sayad (2000) insiste no fato de que, por mais que haja intensos processos de integração social na sociedade de destino, o imigrante terá dificuldade de se sentir como um do lugar; o seu pertencimento e o seu vínculo estarão sempre em outro ambiente. E o retorno, no fundo, em grande parte das situações, é visto como compensação (PERROUD, 2007; DURAND, 2006), mas também carregar algumas exigências para "não virar chacota" (conforme citação a seguir), induzir ou desmotivar novas saídas, visualizar o progressismo e diferenciações 
sociais como seu fruto (formato de casas, comércios, produções variadas). Uma das entrevistadas revela esse processo que se reproduz em várias narrativas que obtivemos em locais de saída.

Não adianta, eles saem, e, daqui muitos fizeram isso. Mas, se tu vais, ver retornam, ou mais hoje, ou mais amanhã, para cá mesmo. Quem foi pra Áustria há mais tempo, muitos ficaram lá. Montaram negócio e hoje levam gente daqui com trabalho seguro. [...]. Tem muito disso aqui na cidade [Treze Tílias]. Meu vizinho foi com toda a família nesses dias. Nessa rua tem no mínimo seis casas, só nessa quadra, de gente que montou isso por causa dos imigrantes; constroem aqui, sempre tem construção e apuram para que, quando voltam no final do ano, esteja pronta. Casas novas com mobília de primeira. Tu vês, as piores casas são dos que não saíram, dos que resistiram em ficar por um motivo ou outro. [...]. Vão, mas voltam. Só que têm que voltar com o dinheiro, né? Senão, vira chacota no bairro" (Esposa de imigrante, que reside em Treze Tílias. Seu esposo ficou por mais de cinco anos entre a Itália e a Áustria. Agora está de volta e montou um grande aviário em sua pequena propriedade rural).

A adaptação e a ausência de um e de outro (do imigrante e de seus familiares) em razão da emigração, acabam marcando e impactando nos sujeitos e nos locais. A distância sentida como imigrante pode ser tão intensa e problemática como a que pode ser produzida na situação de retornado (DURAND, 2006; ASSIS; CAMPOS, 2009). A palavra "acostumar" foi o que mais ouvimos nas narrativas em locais de retorno. "Tentei me acostumar"; "passei por tantas coisas, vou me acostumando"; "difícil de acostumar de novo"; "é o ritmo das coisas daqui, não acontece nada, tudo parece que anda devagar. [...]; parece que falta alguma coisa, que não se está mais preparada para viver aqui. Vi lá [na Itália] que me diziam isso os que retornavam e eu achando que estavam loucos, agora eu vi. [...]. Não tem como se acostumar mais aqui". (Fragmentos de narrativa de imigrante retornado para Pato Branco).

$\mathrm{O}$ emigrante retornado se vê envolto em profundos elementos simbólicos e seus múltiplos significativos que vão desde as aprovações/ reprovações, sentimentos de inveja e de diferenciação, esbanjamentos nos gastos supérfluos (DIAS, 2000; SIQUEIRA, 2006). Na realidade, o emigrante retornado torna-se o centro de atenções e das avaliações do/no cenário do reencontro (DURAND, 2006). Ao que nos pareceu nas entrevistas, a dimensão da mudança, do diferente, do "não ser o mesmo", é lugar comum. "Não gosto muito de falar que achei tudo diferente porque vão dizer que só eu sou perfeito, que voltei de peito estufado, mas é tudo muito estranho, parece que o mundo aquele da gente não é o mesmo". Imigrantes enfatizam a dificuldade ligar os dois mundos e promover reencontros. "[...], por incrível que pareça, pensei várias vezes em retornar de novo. Pensei em ir para os Estados Unidos, não o fiz porque voltei para o magistério, tenho de cuidar melhor da filha adolescente". Podemos perceber que se instala uma descontinuidade entre as pessoas que ficaram e as que partiram. Os fragmentos das narrativas anteriores expõem isso.

A mudança de ambiente produz novas experiências, singulares situações, propiciando reavaliação das anteriores (RAMOS, 2003; DIAS, 2000). Muitas mulheres, no espaço migratório, nos disseram que reavaliam e vivem questionando seus papéis anteriores e quando retornarem, se assim o fizerem, "muita coisa vai ser diferente". Narrativas colhidas de brasileiras entrevistadas na Itália enfatizam a questão das mudanças de papéis de gênero, de novas exigências que recaem para elas, em particular, o envio de dinheiro para quem ficou e que incorporou vínculos de obrigação moral. Elas concebem que mudaram muito com a identidade de imigrante. Entendem que as sociedades são diferentes, suas histórias e formações são específicas e particulares, mas que as condições objetivas e concretas da vida imprimem diferentes exigências e responsabilidades. Porém, como uma entrevistada nos disse que: "[...] não adianta a gente mudar, se eles [de sua família e na comunidade a que pertence] aqui não mudam; dá briga, fica um ambiente pesado; eles deveriam pensar diferente, mas acho que teriam de passar pelo que eu passei fora. Teriam de (e)migrar também".

Afetividades, obrigações e racionalidades econômicas passam pelo crivo das decisões 
subjetivas. A narrativa a seguir revela certo conflito entre desejos de acumular capitais individuais e as obrigações familiares:

Você sabe que aumenta a obrigação com os que ficam. Muitos dos que ficam querem e contam só com o dinheiro que mandamos. Criamos em nós e nos outros a obrigação de mandar dinheiro. Não é por nada, mas conheço vários que estão comigo em Verona há mais tempo do que eu e não arrumaram nada ainda [não acumularam capitais], o que ganham é para o consumo da família. Eu penso que se estou aqui é para ajeitar minha vida. Tenho que agir nesse sentido. (Imigrante brasileiro, há cinco anos na Itália, trabalha como auxiliar de carpinteiro em Verona, oriundo de Cascavel/PR).

Para muitos, o retorno se torna uma obsessão e organizam relações e situações em razão disso. Não há dúvida que fatores culturais e sociais precisam ganhar centralidade nas análises das migrações internacionais e, em particular, quando da análise dos retornos. Optar por um retorno a um lugar distante do de origem pode ocorrer. Soubemos de retornados em de Pato Branco e em Dois Vizinhos que foram à Curitiba, de Nova Prata foram à Porto Alegre, dentre outros; porém, não é a regra, ou melhor, não foi o que observamos com grande expressão.

\section{"Retorno do filho próspero": custos e benefícios do retorno}

Entendemos que imigrantes buscam, em geral, ganhos financeiros e capital humano; os ganhos podem até compensar os custos e sacrifícios; porém, enfatizamos que, tanto emigrar quanto retornar são situações multidimensionais. Retornar com dinheiro no bolso e progredir economicamente é, aos olhos de todos os que ficaram e aos próprios, possibilidade de poder dar um sentido à emigração, à própria ausência (DURAND, 2006; ASSIS; CAMPOS, 2009). Há necessidade do registro do reconhecimento e testemunho de quem ficou; para isso, é bom demonstrá-lo e publicizá-lo mediante aquisição e/ou construção de casa (é o mais comum, pois é imóvel, visível, identificável, quantifica publicamente o valor), de carros, de terra, de montagem de pequenos negócios e serviços.

O capital social adquirido no espaço de origem e as relações pessoais conservadas com o país são também estratégias que se vinculam com o retorno e as migrações no interior do país de origem, inclusive, com o tempo definitivo ou não do retornado. Investimentos posteriores ao retorno poderão acontecer com mais intensidade fora do local de origem, mas antes é necessária a presença nesse. Nessa questão, também fazem parte os cálculos de custos e benefícios, dos rendimentos que não crescem com a mesma intensidade de tempos anteriores.

A satisfação do retorno para alguns pode ser incorporação do desejo de outros em seguir seus passos. Desse modo, as mobilidades vão ganhando dinamismo, os espaços vão sendo recompostos e o local de origem e o de destino passam a ganhar conotações diferentes (ASSIS; CAMPOS, 2009). Para uns não serve mais, para outros é o ideal; para uns é exclusão, para outros é inclusão. A insatisfação que uns tiveram anos antes com o local de origem, torna-se o sonho e projeto de vida e de investimentos agora. Espaços deixados vazios por uns poderão ser preenchidos por outros em ambos os locais. Algumas famílias são recompostas com presença e outras redefinidas com ausências. A terra de origem é o espaço idealizado para voltar (ASSIS; CAMPOS, 2009; SAYAD, 2000); ou seja, ganha sentido a territorialidade vivida, talvez não de uma forma romântica, mas econômico-afetiva. "Eu quis voltar. Naverdade, semprepensei em investir aqui onde tenho os conhecidos, já tenho os freguêses", disse-nos uma cabeleireira em Dois Vizinhos/PR que visitamos em seu espaço de trabalho, a qual esteve por cinco anos entre Itália, Áustria e Inglaterra. Para ela, o local de origem tornou-se um espaço funcional, pois é nele que "já possuía freguês", passou a fazer parte do seu projeto de vida. Diz ela que aprendeu o ofício na Itália, e isso lhe dá certo capital social e saber "para melhor desempenhar aqui e atrair freguês que quer saber como é a vida lá".

O retorno idealizado é aquele que se realiza com "muito dinheiro no bolso", para "viver 
bem aqui" onde partiu. Esse processo conforma e confirma o sucesso da saída (AMBROSINI; BERTI, 2009). Entretanto, um entrevistado enfatizou que "não adianta você voltar com dinheiro se não souber aplicar; ele se some logo" [...]. A sede de investir, de aplicar o dinheiro em alguma coisa, para render logo, já fez gente que voltou cheio de dinheiro para cá e fez retornar de novo em situação pior do que quando foi antes" (Imigrante brasileiro, na Itália há 3 anos, oriundo de Água Doce; trabalha na construção civil). Há relatos de emigrantes que retornaram prósperos e ficaram mais empobrecidos que antes de partir em pouco tempo - "[...] se tu não sabes administrar ou escolher certo onde investir, o que levou quatro ou cinco anos para ganhar, tu detonas em quatro cinco mês".

Vimos que o êxito do retornado induz emigrações de outros do local de origem, pois demonstram a possibilidade de ganhar dinheiro como imigrante. Alguns brasileiros retornaram para o espaço de origem quando conseguiram documentos de permanência ou dupla-cidadania, pois isso lhes permite voltar à Itália quando convier e/ou necessitarem. Nesse sentido, a documentação possui uma dimensão prática de entrada e saída, permite gerenciar melhor a vida nos dois locais, inclusive negócios/investimentos e vida afetivo/ familiar. Um entrevistado do município de Água Doce disse-nos que a dupla cidadania faz dele "[...] um cara de dois mundos; me permite ir à Itália quando tem mais trabalho lá [na confecção de parreirais], e volto no período da safra aqui". O entrevistado é um imigrante retornado e que comprou um caminhão para puxar soja e milho em período de safra. $\mathrm{Na}$ Itália, ele montava empresa de prestação de serviços para viticultores.

\section{“O ir e vir de muitos": presenças e ausências}

Entrevistamos dois irmãos na cidade de Joaçaba/SC, os quais possuem restaurantes no referido lugar; ambos emigraram várias vezes para a Itália e para a Áustria:

[...], foram mais de 15 anos, indo e voltando, até a gente ir se organizando de vez aqui. Nesse lugar a gente conhece, aqui está o nosso povo. Mas o bicho pegou várias vezes. Lembro nas primeiras vezes que retornei e, ele [irmão] também, não tinha como se acostumar aqui. Tudo parecia diferente e, eu querendo botar restaurante. Ficava difícil daí, né. Isso só foi possível depois de muito tempo, muito ralar lá na Itália, voltar pra cá, juntar dinheiro lá e investir aqui. (Entrevista em conjunto com dois irmãos retornados na cidade de Joaçaba/ SC; ambos possuem restaurantes no município; residiram por vários anos na Itália e trabalharam em restaurantes e na agricultura).

Segundo os entrevistados, o retorno pode vir acompanhado por uma forte dose de ilusão nostálgica, que, em pouco tempo, transforma-se em desilusão. Já vimos que voltar com dinheiro no bolso e progredir economicamente é, aos olhos de todos os que ficam e aos próprios, possibilidade de poder dar um sentido à emigração, à própria ausência, de mostrar que o ato de sair não foi privo de resultados e de significados; é o reconhecimento testemunhado do grupo, assim como a construção de uma casa no lugar de origem recorda a ausência, a nega e a atesta ao mesmo tempo. Por isso que o ato de retornar é, também, alimentado por outras dimensões que não a econômica, elementos simbólicos inseridos nos campos culturais e sociais são importantes nesse sentido (CASSARINO, 2013). Insistimos na ideia de que o retorno ao local de origem é uma ação também de ordem moral, como obrigação; é uma experiência que integra e faz parte da vida do migrante; aliás, ele apenas continua sendo migrante se mantiver contatos e presenças com o local de origem; é um sentimento de pertença e de lealdade ao território que marca sua presença e identificação (ASSIS; CAMPOS, 2009; DURAND, 2006).

O retorno definitivo e a ruptura dessa intenção com a volta novamente para a Itália exercem também uma propaganda negativa da situação no Brasil para os que já estão fora, fazendo com que muitos repensem seu desejo de retornar ao país em um curto intervalo de tempo. Vimos em pesquisa de campo em Santa Catarina e no Paraná, muito mais do que no Rio Grande do Sul, a "facilidade com que o pessoal vai e vem"; muitos adotam a estratégia 
de voltar ao país de imigração em períodos sazonais (colheita da uva com máquina, em período de forte trabalho de restauração de prédios e casas, em particular na região do Lago de Garda em período invernal, pois nessa estação os turistas saem das casas e os proprietários fazem reparos). O período pode variar em razão de atividades, remunerações e negócios e/ou atividades no local de origem. Na realidade, são racionalizações e estratégias que permitem que emigrados consigam aliar negócios e famílias, entre presenças e ausências em ambos os locais, manter vínculos que possam ser acionados em alguns períodos, tanto no campo financeiro, quanto na demanda por trabalhadores em determinados setores (SIQUEIRA, 2009). A narrativa de um interlocutor de Luzerna/SC é revelador desse pendularismo:

Fui três vezes e voltei, mas acho que vou de volta ainda [paá Itália]. Aqui é bom, mas tem coisa braba, até pior do que tem lá. Se lá te tratam mal. Aqui tem perigo, o que se ganha, se torra tudo. Cidade pequena, tu sabes, gira pouco dinheiro. Tu não podes arriscar fazer investimento. Acho que vou em período de colher a uva, fico lá uns quatro meses, trago uma boa grana e fico o resto aqui. Tem muito fazendo isso por aqui; os que têm filhos e esposas tão fazendo isso, mas muitas mulheres também. Essas vão em período de turismo, no verão deles para cuidar de idosos [...]; mas tu tens que estar bem amparado lá, fazer um bom cartaz para poder voltar sempre [...]. Tu sabes que o bicho pega para os dois lados. Aqui não ta bom, mas nem lá. Então, a gente vai jogando e vendo o que ta melhor" [O interlocutor investiu na compra de um caminhão transporta cereais para uma empresa do Oeste de Santa Catarina]. (Imigrante retornado; reside na cidade de Luzerna/SC).

Essa possibilidade tende a se firmar e produzir desejos de permanência por mais tempo no país, pois faz com que indivíduos passem a redefinir algumas relações que os mantinham ao seu local de origem, produzir outras internamente com os recursos e as estratégias produzidas por eles e/ou adaptadas às já existentes (DIAS, 2000). É bom que se diga, também, que esses vínculos não são ausentes de conflitos, fator esse que pode também alterar os quadros de permanência. "Agora ele quis ir à Itália; lá é trabalhar e mandar dinheiro. Aqui tem de trabalhar também, mas o ganho é pouco; ele se desconformou. [...]. Depois de sete anos fora, não se acostuma mais aqui e quer trabalhar ainda mais um tempo fora e depois vai ver". (Esposa de imigrante, meio rural do município de Água Doce/SC).

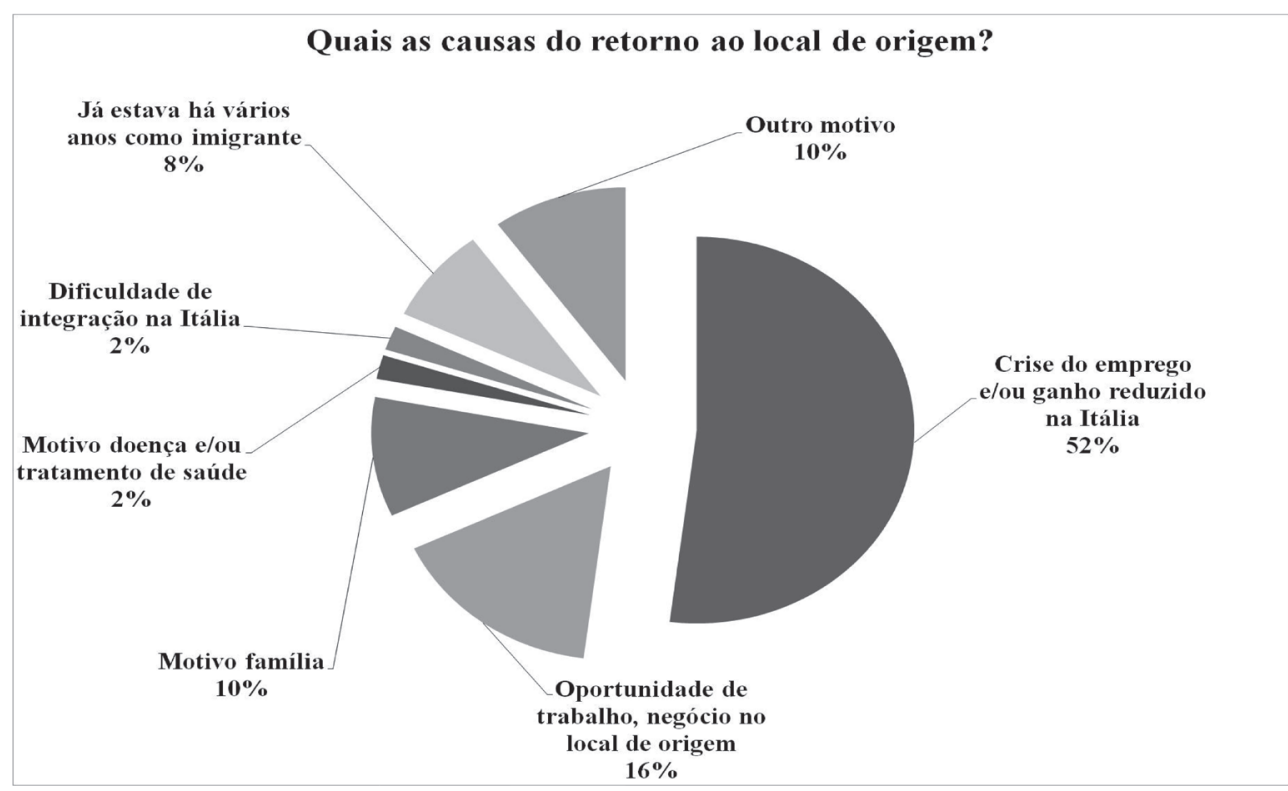

Gráfico 1 - Causas do retorno ao local de origem Fonte: Pesquisa de campo. 
Imigrantes dizem estar mais capacitados ao retornarem; porém, a grande maioria não retorna para atividades que exerciam antes de emigrar; também não exercerão o que faziam na Itália. Precisam reinventarem-se. Das 31 pessoas que indagamos, de uma forma mais estruturada, essas questões, 16 delas responderam que atuam em atividades diferentes, seis em setores que se aproximam (uma cabelereira, na Itália, durante um breve período, exercia essa atividade; um homem, no setor metalúrgico trabalhava como soldador); cinco informaram que sim, ou seja, no setor da construção civil nos dois espaços; entretanto, dois, no local de origem montaram empresas e possuem funcionários; três nas atividades agrícolas ligadas à cultura da uva/vinho; uma não exerce mais atividade dependente, pois se aposentou.

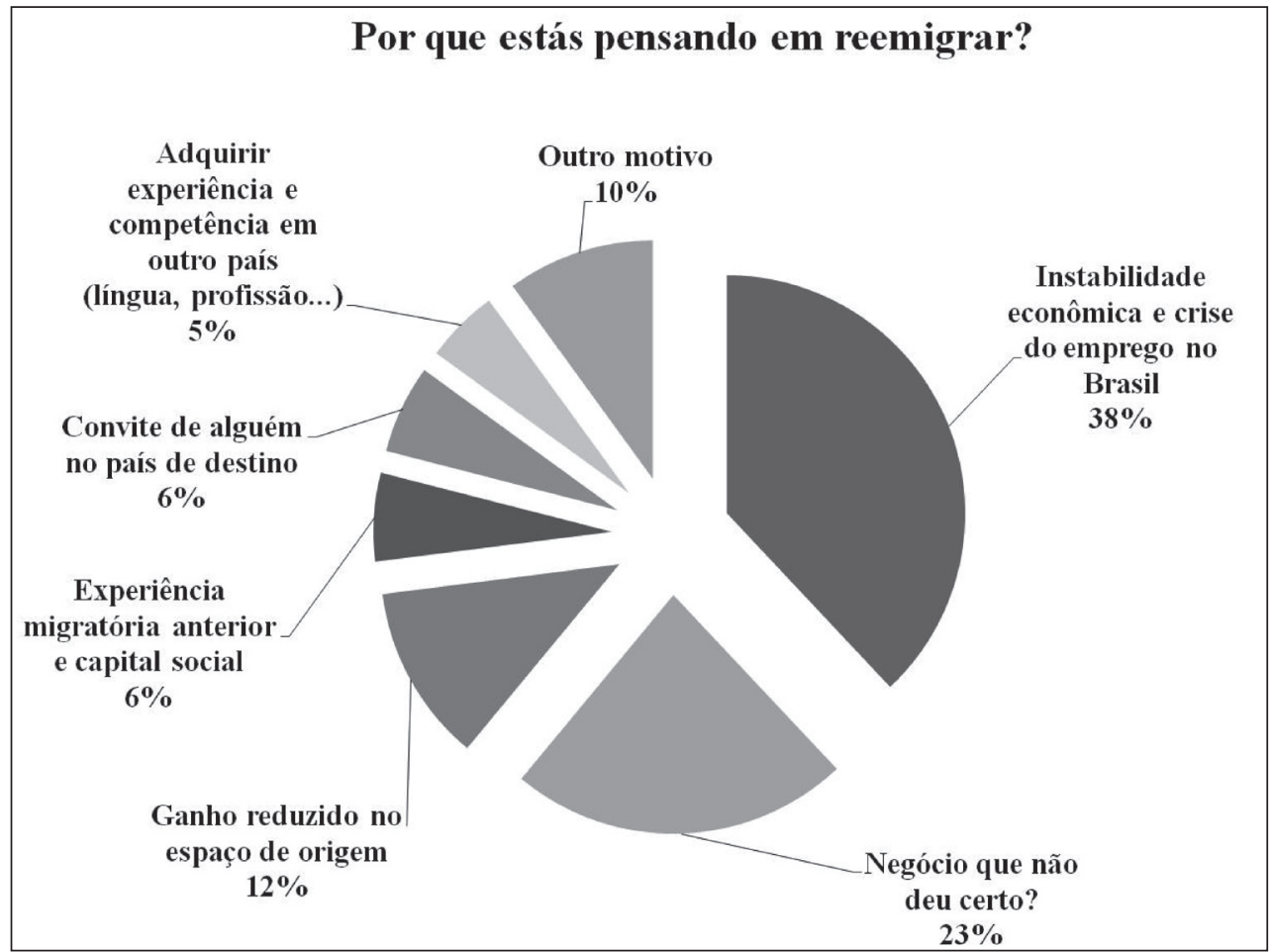

Gráfico 2 - Intenções da reemigração

Fonte: Pesquisa de campo.

Quando imigrantes retornam novamente ao país de imigração, redefine-se a representação do mito do retornoàs origens étnicas (ASSIS; CAMPOS, 2009); a lógica é outra, é a da maximização e racionalização. Nesse sentido, os vínculos culturais são ressignificados. Um imigrante disse que o retorno para ele foi uma nova emigração; "voltei com outra cabeça, e fiquei meio estranho aqui"; disse-nos uma imigrante em Verona, "estou aqui pra ganhar dinheiro"; não se idealiza mais a Itália como pátriamãe, processo esse que faz reconstruir a identidade e "passar por experiências de ida e de volta". As (con) vivências em espaços e as (situ)ações concretas vividas em ambos podem produzir representações que se alteram no decorrer do tempo (CUNHA, 2000).

Imigrantes retornados dizem sentir falta " $d o$ ritmo da vida na Itália". Como imigrantes acabaram perdendo "[...] o ritmo de vida daqui; a gente se sente meio estranho, parece que falta alguma coisa, parece que não se está mais preparado pra viver aqui, é incrível, nem eu acreditava nisso" (retornado que reside em Luzerna/SC).

Essas reemigrações fazem parte "de quem já começou; eu to convencida que é só começar". Segundo Sayad (1999, p. 46), esse processo “[...], deixa as pessoas mais independentes e com desejo de sempre tomar decisões, e uma dessas decisões é 
emigrar sempre". Acreditamos que são produzidos confrontos de expectativas entre ambos os espaços, de origem e chegada. O difícil mesmo, como um retornado nos disse, é restabelecer tempos que ao passado pertencia, "é fazer voltar e ver o que não vi; não vi os filhos crescerem; meu tio que me criou morreu e não pude ir ao enterro. É tanta coisa que não vi e queria ta lá para ver". Lacunas entre tempos se formam e experiências são reinterpretadas e perspectivas alteradas.

\section{Considerações finais}

Vimos que é difícil interpretar as ambivalências e múltiplas diversidades do ato de emigrar e retornar, permanecer e/ou reemigrar se não tivermos em mente processos subjetivos e do contexto temporal vivido pelos imigrantes. Afetividades, saudade, família, os amigos, as redes no país hospedeiro e no espaço de origem, desemprego, ganhos, doenças, obrigações etc. vão se constituindo e produzindo alterações e decisões.

Percebemos que a realidade é dinâmica, ou seja, se permanecer no país de destino não há garantia de tempo, o tempo do retorno também não há e, a volta ao local de origem também pode não ser definitiva. Há um conjunto amplo de fatores em que, para alguns momentos, poderão ser dadas prioridades que, em outros não são mais centrais. Porém, não há dúvida de que a dimensão econômica (trabalho, ganhos, investimentos, empreendedorismo, sustento da família etc.) passam a ser centrais. São aspectos que dão a identidade de emigrante, que justificam e legitimam em boa parte a ação de emigrar.

Insistimos no fato de que precisamos ver as motivações econômicas e não econômicas do retorno, que o retorno pode ser uma etapa do ciclo migratório e, não o fim. Vimos que a dupla cidadania tem favorecido isso (esse vai-e-vem-vai...); que que há múltiplas etapas na construção do retorno; ele pode ser influenciado pelo que originou a saída, bem como pela duração da permanência no exterior e, sem dúvida, pelas situações e experiências que ele ocorre.

Vimos na pesquisa de campo que há dificuldade de readaptação/ambientação do emigrante retornado em razão de remunerações baixas, expectativas frustrantes em termos das condições de vida e de possibilidades de empreender com os recursos já adquiridos pela emigração anterior. Muitos pensam e lançam mão de relações que os permitem reemigrar. Essa é também condicionada por múltiplos fatores, talvez, muito próximos aos que promoveram a saída anterior. Nesse sentido, nenhuma das ações tornase definitiva, nem totalmente a priori definida.

Enfim, há um conjunto amplo e variado de situações, justificativas, explicações, racionalizações que acabam criando realidades de retorno, de volta ao país que emigrou antes, ou a outro. As situações são complexas, tornando-se difícil encaixá-las e agrupá-las em torno de algumas tipificações e/ ou fazer generalizações. As situações específicas revelam diferenciações, vínculos, integrações, sofrimentos, enfrentamentos, racionalizações e decisões contemporaneizadas por múltiplas causalidades, o que demonstra que os migrantes passam a ser sujeitos de relações, interações e que são constantemente desafiados a tomar decisões entre partir e retornar. Há protagonismos, racionalizações movidas pelas duplas ausências e presenças ao mesmo tempo. Uns vão e outros voltam, muitos dos que voltaram, vão de novo, outros não retornam mais a ser emigrantes; porém, permitem a saída de outros membros da família. Assim, as realidades vão se alimentando por múltiplos fatores e heterogeneidades.

\section{Notas}

1 A pesquisa foi financiada pela Università di Verona, Dipartimento Culture e Civiltà, Fondi Cooperint - Cooperazione allo Sviluppo - anno 2017, a qual agradecemos muito pela concessão de bolsa, visto que nos permitiu fazer pesquisa de campo e atualizar bibliografias, bem como intercambiar questões com outros pesquisadores na Itália sobre o tema da imigração nos meses de janeiro e fevereiro de 2018.

2 Tivemos a oportunidade de estudar sobre a imigração brasileira na Itália in loco em vários momentos nos últimos 12 doze anos por ocasião de dois estágios de pósdoc (2005 e 2011) nas Universidade de Verona e Milão respectivamente; foram três oportunidades de estágio de professor visitante na Universidade de Verona por meio do edital Cooperint - Cooperação Internacional 
- a última oportunidade foi entre os meses de janeiro e fevereiro de 2018. Portanto, construímos um lastro amplo de relações e interconhecimento com imigrantes brasileiros no referido país. Alguns dos estudos estão em: TEDESCO, J. C. Imigração e integração cultural: interfaces. Passo Fundo/Santa Cruz do Sul: UPF Editora/ Edunisc, 2005; Estrangeiros, extracomunitários e transnacionais. Porto Alegre: EdiPUCRS, 2009; . Entre Raízes e Rotas: identidades e culturas em movimento. Itajaí: Univali; Passo Fundo: UPF Editora, 2012.

3 Identificamos algumas questões relacionadas à emigração de brasileiros para a Áustria ou, então, retornados desse país, em razão de que muitos dos brasileiros que emigraram para a Itália, acabam indo também para a Áustria, ou vice-versa, principalmente os oriundos de alguns municípios do Oeste de Santa Catarina. O município de Treza Tílias é constituído, em grande parte, pela colonização austríaca, fato esse que promove muita saída de brasileiros para esse país, tanto do referido município, quanto de outros de seu entorno (Água Doce, Luzerna e Joaçaba), fruto de redes que se constituem entre migrantes. Desse modo, migrantes circulam pelos dois países, otimizam as possibilidades que as redes promovem para encontrar espaços alternativos de trabalho. Portanto, retornados podem ter migrado para os dois países.

4 Os entrevistados não serão identificados nominalmente no texto; optamos por informar apenas o local de origem, onde está no momento da entrevista, há quanto tempo está na Itália e onde trabalha.

5 Os “gemellagios" são acordosde cooperação, alimentados e justificados étnico-regional e historicamente entre dois espaços transnacionais (no caso, entre Brasil e Itália), em múltiplas áreas, com preponderância econômica (indústria, comércio, turismo, agricultura, cursos de profissionalização, espaço de trabalho para imigrantes brasileiros na Itália etc.), entre determinadas regiões da Itália (em geral, pequenos municípios) com alguns municípios do Brasil. Em nosso país, estão mais concentrados na região sul, com maior preponderância no Rio Grande do Sul; na Itália, os acordos concentramse mais no norte/nordeste (Vêneto, Lombardia, Trento), regiões essas de maior fluxo de emigrantes para o sul do Brasil entre a segunda metade do século XIX até 1914. Ao que nos parece, vêm coroar esse processo histórico todo e imprimir novas ações e possibilidade em meio a outros processos associativos e de vínculos institucionais de caráter étnico de italianos do início do século XXI.

\section{Referências}

AMBROSINI, Maurizio. Un'altra globalizzazione. La sfida delle migrazioni transnazionali. Bologna: Il Mulino, 2008.
Transnazionalismi e globalizzazione dal basso: questione teoriche e approfondimento empirici. In: AMBROSINI, Maurizio.; BERTI, Fabio. (a cura di). Persone e migrazioni. Milano: Franco Angeli, 2009, p. 21-42.

Richiesti e respinti. L'immigrazione in Italia. Come e perché. Milano: Il Saggiatore, 2010.

AMBROSINI, Maurizio.; BERTI, Fabio. (a cura di). Persone e migrazioni. Milano: Franco Angeli, 2009.

ASSIS, Gláucia de Oliveira. Estar aqui... estar lá... Uma cartografia da vida entre dois lugares. 1995. 170f. Dissertação (Mestrado em Antropologia Social) - Programa de Pós-Graduação em Antropologia Social, Florianópolis, 1995.

.; CAMPOS, Emerson Cesar de. De volta para casa: a reconstrução de identidades e emigrantes retornados. Tempo e Argumento. Florianópolis, v. 1, n. 22, p. 80-99, jul./dez. 2009.

BAUMAN, Zygmunt. Dentro la globalizzazione. Le conseguenze sulle persone. Roma-Bari: Laterza, 1999.

Estranhos à nossa porta. Rio de Janeiro: Zahar, 2017.

BERTI, Fabio. Globalizzazione, migrazioni internazionali e cooperazione allo sviluppo. In: AMBROSINI, Maurizio.; BERTI, Fabio. (a cura di). Persone e migrazioni. Milano: Franco Angeli, 2009. p. 44-64.

CARITAS/MIGRANTES. Dossier statistico 2011. Roma: Idos Edizioni, 2011.

CASSARINO, Jean-Pierre. Teorizando sobre a migração de retorno: uma abordagem conceitual revisitada sobre migrantes de retorno. REHMU, Brasília, ano XXI, n. 41, p. 21-54, jul./dez. 2013.

FONDAZIONE IDOS. Dossier Statistico Immigrazione 2017. Roma: Idos, 2017.

CUNHA, Aparecido Soares. Migração de retorno 
num contexto de crises, mudanças e novos desafios. Anais do Encontro da Associação Brasileira de Estudos Populacionais, Caxambu, MG, 2000.

DECIMO, Francesca. Quando emigrano le donne. Bologna: Il Mulino, 2005.

DIAS, Juliana Braz. A volta do filho próspero: emigrantes cabo-verdianos retornados e seus familiares. In: TEIXEIRA, Carla Costa (Org.). Em busca da experiência mundana e seus significados: Georg Simmel, Alfred Schutz e a Antropologia. Rio de Janeiro: Relume Dumará, 2000. p. 56-73.

DURAND, Jorge. Los inmigrantes también emigran: la migracion de retorno como corolário del proceso. REMHU - Revista Interdisciplinar da Mobilidade Humana, Brasília, ano XIV, n. 26/27, p. 167-189, 2006.

HERRERA, Gomez.; CARILLO, Massimo, Carmassi. Trasformazioni familiari nel'esperienza migratória ecuadoriana. Uno sguardo dal contexto di partenza. Rivista Mondi Migranti, Milano, n. 3, p. 63-83, 2010.

MARTES, Ana Cristina Braga; SOARES, Weber. Remessas de recursos dos imigrantes. Estudos Avançados, v. 20, n. 57, p. 41-54, maio/ago. 2006.

PERROUD, Mélanie. Migration retour ou migration detour? Diversité des parcours migratoires des brésiliens d'ascendance japonaise. Remi - Revue Européenne des Migrations Internationales, Paris, v. 23, n. 1, p. 49-70, 2007.
RAMOS, Silvana Pirillo. Hospitalidade e migrações internacionais. O bem receber e o ser bem recebido. São Paulo: Aleph, 2003.

SACCO, Giuseppe. Italia addio. Démographie et immigration. Revue Française de Géopolitique. Paris: Sorbonne, n. 17, p. 113-143, 2007.

SAYAD, Abdelmalek. La Double absence. Paris: Ed. Du Seuil, 1999

- O retorno: elemento constitutivo da condição do migrante. Revista Travessias, v. 13, n. especial, p. 7-32, jan. 2000.

SIQUEIRA, Sueli. Migrantes e empreendedores na microrregião de Governador Valadares: sonhos e frustrações no retorno. 2006. 201 f. Tese (Doutorado em Sociologia Política) - Programa de PósGraduação em Sociologia Política, Universidade Federal de Minas Gerais, Belo Horizonte, 2006.

\section{Sonhos, sucesso e frustrações na} emigração de retorno: Brasil/Estados Unidos. Belo Horizonte: Argumentum, 2009.

SOARES, Weber. Da associação entre os retornados internacionais e os intermediários da rede migratória valadarense. REMHU, São Paulo, n. 32, ano XVII, p. 47-59, 2009.

ZINCONE, Giovanna. Familismo legale. Come (non) diventare italiani. Roma-Bari: Laterza, 2006. 